The Geneva Papers on Risk and Insurance, 21 (No. 78, January 1996), 50-76

\title{
The Theoretical Considerations Underlying the Risk Reserve Process and the Practical Assessment and Control of the Capital Required (Risk-Based Capital)
}

\author{
by Eberhard Müller* and Michael Reischel**
}

\section{Introduction}

Although there are instances enough of the derivation of prescriptive factors from a purely descriptive explanation of the development of risk reserves over time, it must be acknowledged that the application to the solution of the practical problems remains unresolved. On the one hand this is no doubt due to the fact that there are no generally accepted governing criteria and on the other that a rational evaluation of the risk reserve process presupposes the existence of risk reserve utility functions. This condition depends in turn on a comprehensive assessment of the risk preference and utility functions of the decision maker(s), in particular in the light of periodical considerations of the risk reserve process and comes up against almost insuperable objections in practice.

Increasingly therefore, instead of specifying a uniform and consistent risk preference function, one encounters attempts to derive a quantitative approach based on a combination of the evaluation of individual aspects, whereby the theoretical correctness of the solution in respect of each aspect is less important than the bringing together of the evaluated individual aspects into an overall formulation capable of practical application. It is in this context that one should view the efforts of the American «National Association of Insurance Commissioners» (NAIC) to establish a model which would enable a comparison between the available capital («Total Adjusted Capital», TAC) and the required capital («Risk-Based Capital», RBC) covering all underwriting risks and non-insurance risks of insurance companies.

\footnotetext{
* Manager, Hannover Reinsurance, Hannover.

**Chairman of the Board, Hannover Reinsurance, Hannover, $\uparrow$ 04.06.1995.
} 
Here again the attempt is to find a practical solution. Clearly this does not and indeed can not lead to a theoretically «correct» solution.

\section{The extended risk reserve process}

In the scientific insurance literature it is customary to describe the risk business of an insurance company in terms of the so-called risk reserve process. In the simplest case this consists in the development of the starting reserve of an insurance company resulting from premium income and claims outgo.

With the exception of the starting reserve, these are random variables and in the 'classical form' this statement can be set out as follows:

$$
\begin{aligned}
& \text { Risk reserve }=\text { Starting reserve }+ \text { Premium variable } \text { - Claims variable } \\
& \mathrm{R}(\mathrm{t})=\mathrm{R}(0)+\mathrm{P}(\mathrm{t})+\mathrm{X}(\mathrm{t})
\end{aligned}
$$

The starting point for our subsequent considerations is based on the statement of the risk situation of an insurance company in terms of the extended risk reserve process. In addition to the starting reserve and the underwriting risk in the narrowest sense the risk reserve available at time $t \in[0, \infty)$ is determined by the following factors:

- Investment earnings (excluding technical interest in life assurance and attributed interest income in discounted non-life insurance),

- The proceeds of releases and revaluations (e.g. the release of hidden reserves),

- Expenses (expenses of management),

- Dividends (distributions on capital),

- Residual items (e.g. releases from equalisation reserves, additional capital subscriptions).

If each of these components is identified by a separate random variable the development can be formulated as follows:

$$
R(t)=R(0)+P(t)-X(t)+Y(t)-K(t)+V(t)-W(t)+\Delta(t)
$$

Where:

$\mathbf{R}(0)=$ Starting reserve of the process (Original capital)

$P(t)=$ Premiums up to time $t$

$X(t)=$ Claims up to time $t$

$Y(t)=$ Investment earnings up to time $t$

$K(t)=$ Management expenses up to time $t$

$V(t)=$ Incidental proceeds of disposals/revaluations to time $t$

$W(t)=$ Distributions (dividends) up to time $t$

$\Delta(t)=$ Residual items (e.g. increases in capital) up to time $t$ 
For each particular random variable an assumption is made as to the expected value and variance (together with higher moments if applicable). The interdependence of the random variables over time (e.g. Markoff characteristic) and with each other (correlation, stochastic dependence) is separately considered within the framework of the particular investigation.

Given $\mathrm{Y}(\mathrm{t})=\mathrm{K}(\mathrm{t})=\mathrm{V}(\mathrm{t})=\mathrm{W}(\mathrm{t})=\Delta(\mathrm{t}) \equiv 0$ and transforming to operational time $\hat{\mathrm{t}}$, the 'classical' risk reserve process is obtained in the form:

$$
R(\hat{t})=R(0)+P \cdot \hat{t}-X(\hat{t})
$$

The claims outgo $X(\hat{t})$ is assumed to be a function of the premium income. P represents the 'premium rate per unit of time' and $[0, \hat{t})$ the interval of time over which the premium $P \cdot \hat{t}=\hat{t}+\lambda \hat{t}$ (where $\lambda>0 \triangleq$ additional security factor) is precisely achieved, with the premium accruing evenly over the time interval.

There are numerous analyses of the 'probability of ruin' in respect of the development in (2.3). Generally four stages are considered, from continuous probability of ruin with infinite time scale to the probability of a one-year loss. In deriving the various probabilities of ruin the time parameter $\hat{\mathrm{t}}$ can, in a comprehensive description, encompass the following areas $\mathrm{T} \subset[0, \infty)$ e.g.:

$\mathrm{T}_{1}:=[0, \infty),($ continuous time parameter, infinite time scale)

$\mathrm{T}_{2}:=[0, \tau)$, where $\tau \in(0, \infty)$ (continuous time parameter, finite time scale $\tau$ )

$T_{3}:=\{k \cdot d: k=0,1, \ldots\}$, where $d \in(0, \infty)$ (discrete time parameter, infinite time scale)

$T_{4}:=\{\mathbf{k} \cdot \mathbf{d}: \mathbf{k}=1,2, \ldots, \mathbf{n}\}$, where $d \in(0, \infty), \mathbf{n} \in \mathbf{I N}$ (discrete time parameter, finite time scale $\mathbf{n} \cdot \mathbf{d}$ )

In a special case of $T_{4}$ a single point value with the element $m \in I N$ is selected and the 'development' is observed of the outcome of $R(m) \mid R(m-1)$ which results if the probabilities of outcome $R(m)$ at time $m$ are investigated given that the outcome $R(m-1)$ at time $(\mathrm{m}-1)$ is known.

Consideration of this one year probability of loss can be an intelligent first approach to assessing and controlling insurance companies and has in practice influenced (albeit implicitly) the development of «Risk-Based Capital» in the USA.

\section{The discrete development of available capital (TAC) as a partial development of the extended risk reserve process.}

The measurement of an actual risk reserve process is in itself a major source of difficulty in the assessment. The practical problems of reserving make it virtually impossible to determine the actual situation of a continuous risk reserve process at any selected point of time. For simplicity, the measurement is generally restricted to the point of time to which the accounts are drawn up (e.g. the year end, also in USA quarterly). Every assessment of the development is based on a number of time intervals corresponding to the type $T$ in the foregoing section. However in what follows the actual point of time will generally be assumed instead of the 'operational time'. 
The 'available capital' (Total Adjusted Capital, TAC) at an accounting date consists in the USA principally of the 'surplus' stated in the balance sheet of an insurance company i.e. the surplus of the Assets over the Liabilities. From the results for the year this surplus development can be represented as:

where:

Balance Sheet amounts Profit and Loss account amounts

$S\left(t_{n}\right)=$ 'Surplus' at accounting time $\left(t_{n}\right)$

$S\left(t_{n-1}\right)=$ 'Surplus' at previous accounting time

$\mathrm{Z}\left(\mathrm{t}_{\mathrm{n}}\right)=$ Additions to surplus arising in the period $\left[\mathrm{t}_{\mathrm{n}-1}, \mathrm{t}_{\mathrm{n}}\right)$ from premiums, interest, realisation profits, capital additions and similar

$E\left(t_{n}\right)=$ Reductions in surplus arising in the period $\left[t_{n-1}, t_{n}\right)$ e.g. on account of claims, expenses, write downs, distributions

For practical purposes it is recommended to equate the extended risk reserve development with the surplus calculation at the times $t_{n} \in T_{3}$ :

$$
\mathrm{S}\left(\mathrm{t}_{\mathrm{n}}\right):=\mathrm{R}\left(\mathrm{t}_{\mathrm{n}}\right) \quad \mathrm{t}_{\mathrm{n}} \in \mathrm{T}_{3}
$$

Equation (3.2) will no longer describe the complete risk reserve process but on the other hand pragmatic measures become available for the assessment and, where relevant, control of the discrete development $S\left(t_{n}\right), n=1,2, \ldots$ based on data determined by the annual results.

There are two totally different objectives underlying such assessment and control which must be distinguished from each other.

a) The objectives of the Executive of the company itself (such as the management and the supervisory board) in relation to decisions concerning the achievement of the firm's aims

b) The objectives of (state) supervisory bodies in relation to their supervisory responsibility for the protection of policyholders' interests, third party claimants and, where relevant, proprietors (e.g. small shareholders)

Whilst the majority of studies into the control of the risk reserve process are undertaken from the business point of view, it is the supervisory aspect which is the primary consideration in this paper and in particular the far advanced studies in USA to determine whether a concrete 'surplus development' meets a required standard of security and what measures it may be necessary to introduce to achieve this standard.

\section{The RBC approach in USA}

\subsection{Aims and procedures for the determination of a risk-based minimum capital} requirement for US insurers

\subsubsection{Initial steps and RBC regulation for US Life insurers}

As a result of growing concern about the financial stability of insurance companies in USA at the end of the 1980s, the 'National Association of Insurance Commissioners' 
(NAIC) decided in 1990 to strengthen the US-wide supervisory standards and to develop minimum requirements for the supervisory regulations of the individual federal states. One of the six problem areas to be tackled was the establishment of standards accepted US-wide for the minimum risk-based capital requirement ('Risk-Based Capital', RBC)of insurance companies.

In December 1990, the NAIC set up two working groups, one for Life/Health insurers and the other for Property/Casualty insurers. The consecutive discussions showed that this was one of the most demanding problems ever to be solved in the area of insurance supervision. Although the concept of risk-based capital had been known in the banking sector for some years and RBC models were in existence in some areas of the insurance market (e.g. the rating agencies) it appeared that the development of a uniform and consistent RBC formula equally applicable for all companies was well-nigh impossible.

It must therefore have been all the more surprising that, in December 1992, standards for Life/Health insurers were promulgated, followed in December 1993 by standards for Property/Casualty insurers. This was however achieved only at the expense of some serious qualitative omissions and some «heroic» simplifications. For example in respect of the catastrophe risk and the treatment of reinsurance.

Apart from the risk components and their assessment which will be considered in more detail, the regulations have a uniform structure which can very briefly be set out as follows (see also Exhibit 1).

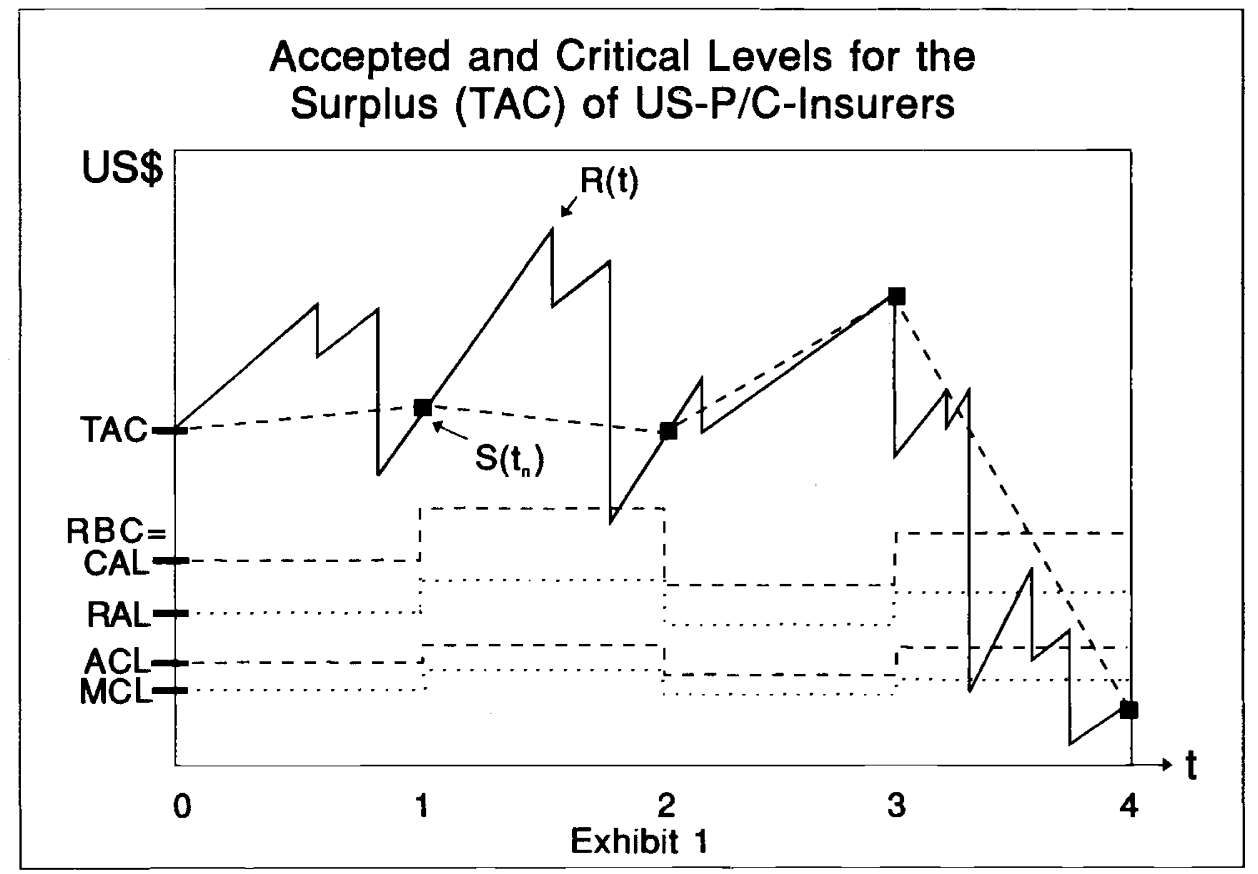


At the balance sheet date the actual available capital (TAC) is established. The RBC, being the minimum capital requirement is then determined from an evaluation of the overall risk situation of the company and this is compared (analogous to the EC regulations) with the TAC. Providing the TAC exceeds the RBC there is, generally speaking, no necessity for intervention by the supervisory authority. If, however, the TAC is becoming increasingly inadequate, the supervisory authority can intervene at one of four possible stages:

1. Company Action Level (CAL): If this level is breached, the supervisory authority can demand an explanation from the company as to the cause of the deficiency and how it is intended to reestablish an adequate capitalization.

2. Regulatory Action Level (RAL): Below this level, in addition to the passive request for a plan for corrective action, the supervisory authority can order measures to be taken for the restoration of the minimum capitalization.

3. Authorized Control Level (ACL): This level sets a 'hard' intervention point below which the supervisory authority can enforce measures for the rehabilitation or liquidation of the company.

4. Mandatory Control Level (MCL):At this level the supervisory authority is obliged to take over the responsibility for the company and to institute rehabilitation or liquidation proceedings.

This basis of control for Life/Health insurers for each annual accounting period from the year of account 1993 is illustrated in the form of a flow chart in Exhibit 2. The calculation of the RBC takes into account risk evaluated capital elements for asset risks, insurance risks, interest risks as well as general business risks which will not be further considered here (but see also section 4.2 as regards Property/Casualty insurers). A special feature in relation to Life/Health insurers is the inclusion also of a trend test if the TAC exceeds the RBC by 'only' $25 \%$. If, on the basis of the data for the last 3 years, this trend test is unsatisfactory, this in itself is a qualification for the first stage of intervention.

\subsubsection{Refinements and RBC regulations for US Property/Casualty insurers}

The setting of RBC calculation standards in the Property/Casualty sector proved to be much more difficult than in the Life insurance sector. On the one hand this arose from the more complex risk structure of the different branches with their differing patterns of claims settlement and differing susceptibilities to social changes compared with general business experience (e.g. in jurisdiction) but on the other hand from the almost insoluble exercise of setting uniform standards applicable to all Property/Casualty companies.

It is therefore scarcely to be wondered at that the first proposals provoked fierce debates, inter alia as to the treatment of reinsurance and these debates have not subsided with the promulgation of the standard as a binding regulation.

In procedural terms the regulation for Property/Casualty insurers was closely modelled on that applicable to Life insurers which had been published one year earlier (see Exhibit 3), with the exception that no trend test is required to be met where the minimum 


\section{Risk Based Capital Calculation Principle for US-Life Insurers}

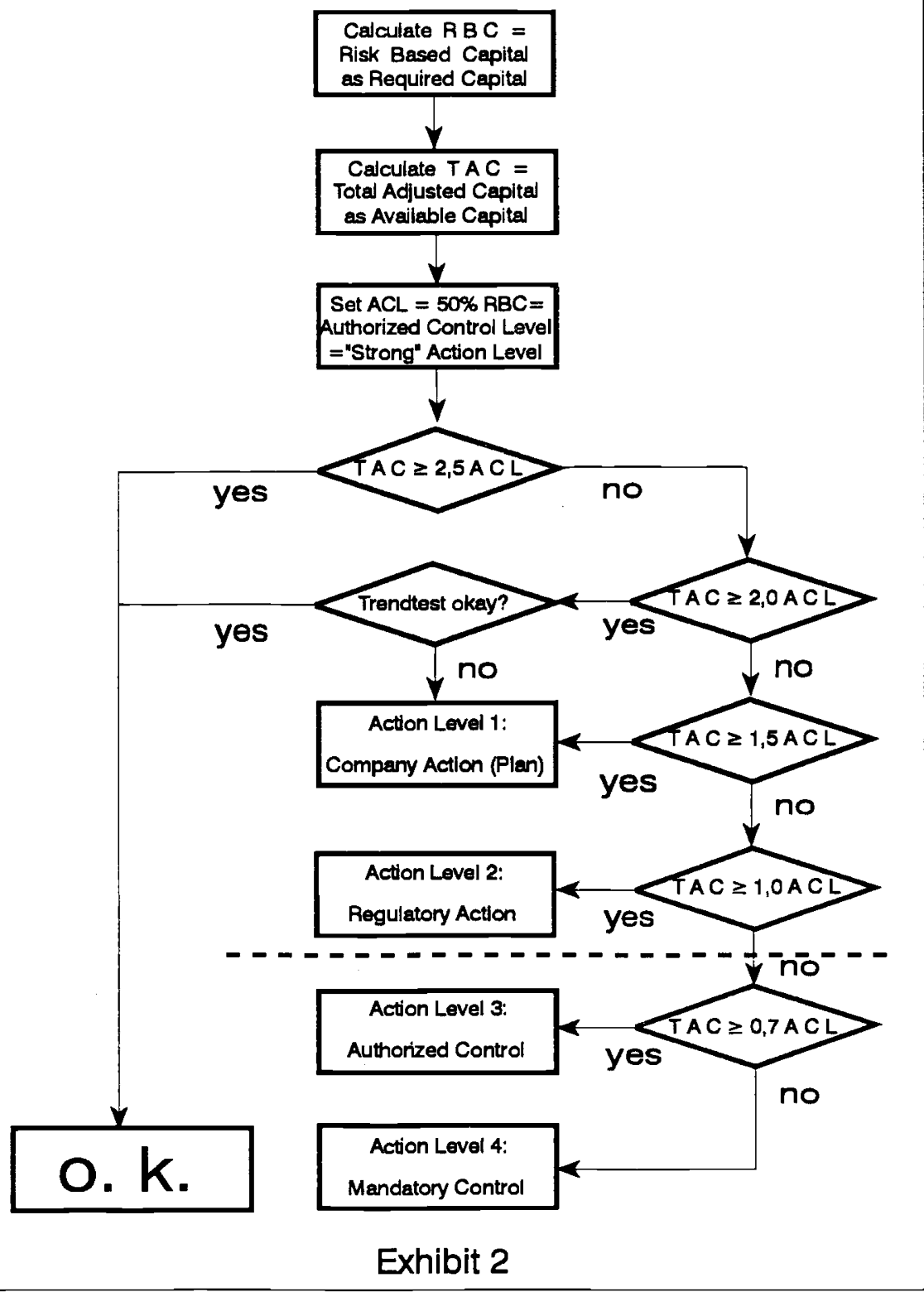




\section{Risk Based Capital \\ Final Calculation Principle for US Property/Casualty Insurers}

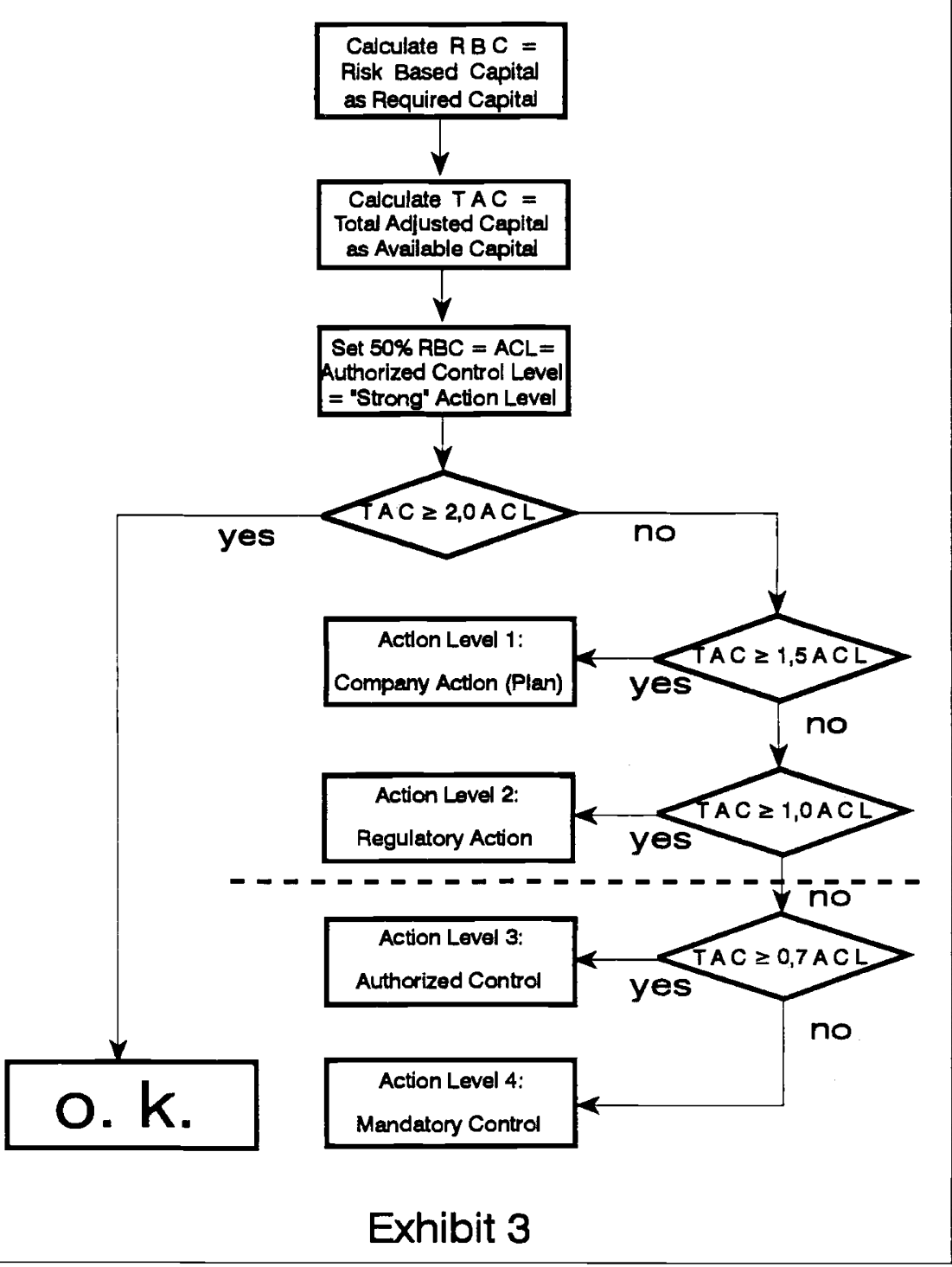


level is only marginally exceeded. In any event the minimum level will be increased in two stages over the next two years by $25 \%$ in total.

Whilst, as in the Life insurance sector, the RBC will be openly calculated and published, advertising based on the $\mathrm{RBC}$ or on the $\mathrm{RBC}$ ratio $\left(=\frac{\mathrm{TAC}}{\mathrm{RBC}}\right)$ and any use of the $\mathrm{RBC}$ ratio for ranking purposes is forbidden. Only the future will tell how this apparently somewhat naive instruction will work in practice. The inclusion in independent rating systems of calculation rules similar to those laid down by the supervisory authority does not appear to be forbidden so that slightly modified forms of RBC-ranking may possibly emerge under other names.

The area of application of the new regulations initially covers all the larger companies or those operating in more than one US federal state with some exceptions e.g. pure financial and mortgage guarantee insurers. Dormant companies and those in liquidation (approx. 7.6\% of all companies) are not subject to the regulations. Allowing for small companies (annual premium income less than US $\$ 2 \mathrm{~m}$.) only operating in one federal state which account for $13.2 \%$ and special exemptions for $7.5 \%$, the rules described in the following paragraphs apply from the year of account 1994 to the remaining $71.7 \%$ of all insurers and reinsurers.

In our description of the regulations we attempt a generalised formalisation along the lines of the components of the extended risk reserve process described above and to this extent distinguishable from the original regulations and the discussion thereof. On the other hand this leads to the possibilities of an improved analytical treatment without thereby intending to arrive at a precise probabilistic analysis.

A further, not unimportant, aspect is the relative brevity and transparency with which the complex definitions in the supervisory rules can be formally described.

\subsection{The Risk-Based Capital formula for US Property/Casualty insurers}

\subsubsection{The risk categories taken into account}

The calculations are based on the 4 (or 5) risk categories

$\mathrm{R}_{\mathrm{K}}(\mathrm{t})=\mathrm{RBC}$ for asset risks

$\mathrm{R}_{\mathrm{A}}(\mathrm{t})=\mathrm{RBC}$ for off-balance sheet risks (including growth)

$R_{F}(t)=R B C$ for credit risk (including reinsurance)

$R_{V}(t)=R B C$ for underwriting risks wherein:

$R_{V}(t)=R_{Q}(t)+R_{P}(t)$

$R_{Q}(t)$ being the loss reserve risk $R B C$ and

$R_{P}(t)$ being the premium risk $R B C$

The fundamental approach is to separate each risk category $X \in\{K, A, F, Q, P\}$ into $n_{x}$ subsidiary categories and to assign a weighting factor to the basic monetary value of each of these subsidiary categories (e.g. realisation values of investments, reserve funds or writ- 
ten premiums) so that the products thereof amount to the risk capital required to provide the desired degree of security.

The generalised formula is

$$
\mathrm{R}_{\mathrm{X}}(\mathrm{t})=\sum_{\mathrm{i}=1}^{\mathrm{n}_{\mathrm{X}}} f_{\mathrm{X}_{\mathrm{i}}}(\mathrm{t}) \cdot \mathrm{B}_{\mathrm{X}_{\mathrm{i}}}(\mathrm{t}) \quad \mathrm{X} \in\{\mathrm{K}, \mathrm{A}, \mathrm{F}, \mathrm{Q}, \mathrm{P}\}
$$

where $f_{\mathrm{xi}}(\mathrm{t})=$ the $\mathrm{i}$ th. factor of category $\mathrm{X}, \quad \mathrm{i}=1, \ldots, \mathrm{n}_{\mathrm{x}}$

and $B_{x i}(t)=$ the $i$ th. basic value of category $X, \quad i=1, \ldots n_{x}$

This will be modified when adjustments to the vector product are considered to be necessary for the RBC assessment.

Adjustments may arise (see 4.2.3.1 to 4.2.3.4 below) from:

- Consideration of risks arising from increased concentration or peaks in individual elements within the category under review (e.g. concentration of investment securities in the case of the asset risk or peak insurance business classes in the case of the underwriting risk),

- Consideration of risks where the experience of a particular company departs significantly from that of the industry as a whole (e.g. in relation to loss ratios, loss development and growth),

- Consideration of risk reduction where part of the underwriting risk is transferred to the policyholder (e.g. additional premiums related to claims experience),

- Consideration of risk reduction arising under particular contracts (claims made policies).

\subsubsection{The covariance formula}

Finally a further adjustment is made to allow for the large degree of non-correlation between the individual elements (covariance adjustment), given that the summation of these elements may in part arise across various risk categories (see Exhibit 4).

$$
\operatorname{RBC}(t)=R_{0}(t)+\sqrt{\sum_{i=1}^{5} R_{i}^{2}}(t)
$$

$\mathbf{R}_{0}(\mathrm{t})=\mathrm{RBC}$ component from investments in affiliated companies, including the RBC component for deposits and contingent liabilities, at time $t$

$\mathrm{R}_{1}(\mathrm{t})=\mathrm{RBC}$ total for asset risks at time $\mathrm{t}$ for fixed interest securities and short term investments including adjustments for Bond size and asset concentration

$\mathrm{R}_{2}(\mathrm{t})=\mathrm{RBC}$ total for asset risks at time $\mathrm{t}$ for equities and real estate including adjustment for equity concentration

$\mathrm{R}_{3}(\mathrm{t})=50 \%$ of the $\mathrm{RBC}$ total for receivables in respect of ceded reinsurance and miscellaneous receivables 
RBC-Formula for US Property/Casualty Insurers Classification of Risk Categories

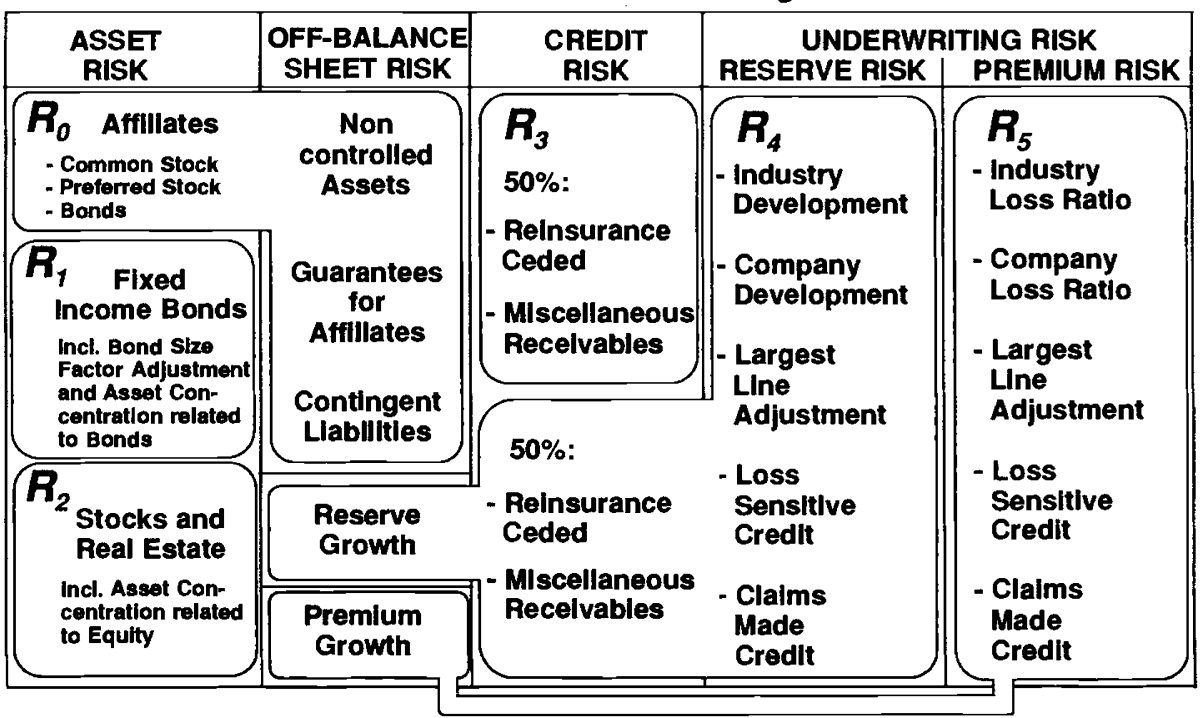

Exhibit 4

\section{Allocation of RBC Charges for US Property / Casualty Insurers As-lf 1991 Industry Aggregates (excl. Covariance Adjustment)}

Primary Insurers

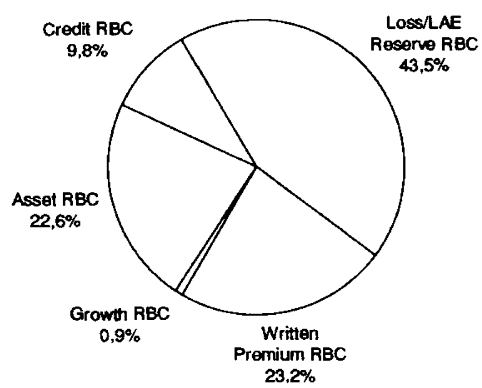

Reinsurers

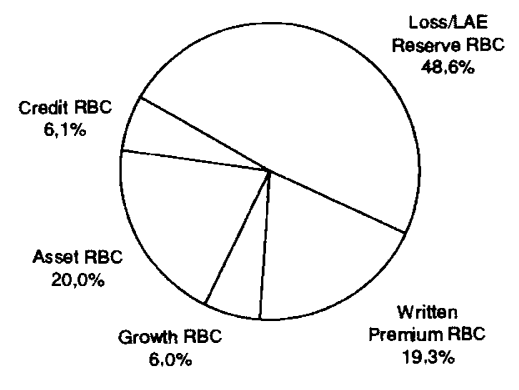

Exhibit 5 
$R_{4}(t)=R_{3}(t)+R B C$ component for the reserving risk

$\mathrm{R}_{5}(\mathrm{t})=\mathrm{RBC}$ component for the premium risk

In practice, this covariance adjustment produces a significant reduction in the RBC, of the order of one-third compared with a simple summation of the component elements(see Exhibit 5).

As from 1996, the first intervention stage, the 'company action level' will be initiated if the actual capital TAC does not cover the RBC thus calculated. In the years 1994 and 1995 a somewhat milder intervention level will apply in accordance with the following formula:

(4.3) $\operatorname{CAL}(t)=2 \cdot \operatorname{ACL}(t)=2 \cdot c_{t} \cdot \operatorname{RBC}(t)$ where $c_{t}= \begin{cases}0.4, & t=1994 \\ 0.45, & t=1995 \\ 0.5 & t \geq 1996\end{cases}$

Where CAL is 'Company Action Level' - Capital

$\mathrm{ACL}$ is 'Authorized Control Level' - Capital

With the substitution:

$\mathrm{R}_{3}(\mathrm{t})=0.5 \mathrm{R}_{\mathrm{F}}(\mathrm{t}) \quad\left(\mathrm{R}_{\mathrm{F}}(\mathrm{t}) \stackrel{\wedge}{=}\right.$ total credit risk $)$ and

$\bar{R}_{4}(t):=R_{4}(t)-R_{3}(t)$ (reserve risk with credit risk eliminated)

the covariance formula becomes

$$
R B C(t)=R_{0}(t)+\sqrt{R_{1}^{2}(t)+R_{2}^{2}(t)+\left(0.5 R_{F}(t)\right)^{2}+\left(0.5 R_{F}(t)+\bar{R}_{4}(t)\right)^{2}+R_{5}^{2}(t)}
$$

The credit risk (principally the risk in respect of ceded reinsurance) is thus explicitly shown and provides a basis for a differential analysis which will give meaningful results in respect of the credit risk.

Inter alia, this facilitates an explicit investigation of the effect of reinsurance cessions on the $\mathrm{RBC}$ requirement.

In the USA the most significant component is the risk of underreserving. An analysis by NAIC of 1991 results showed that for US direct insurers $43.5 \%$, and for US reinsurers $48.6 \%$ (nearly half!) of the RBC requirement (before covariance adjustment) arose in respect of the reserve risk (see Exhibit 5). This was followed by the premium risk accounting for $23.2 \%$ of the RBC for direct insurers and $19.3 \%$ for reinsurers. The asset risk accounted for $22.6 \%$ for direct insurers and $20.0 \%$ for reinsurers. Less significant were the credit risk $(9.8 \%$ for direct insurers and $6.1 \%$ for reinsurers) and the growth risk which at $0.9 \%$ had scarcely any impact for direct insurers but contributed $6.0 \%$ of the total RBC in the case of reinsurers. 


\subsubsection{The most important risk categories considered individually}

\subsubsection{The reserve risk}

We commence our detailed analysis of the calculation rules with the reserve risk in view of its significance. In the first place the generalised formula (4.1) applies here also:

$$
\mathrm{R}_{\mathrm{Q}}(\mathrm{t})=\sum_{\mathrm{i}=1}^{\mathrm{n}_{\mathrm{v}}} f_{\mathrm{Qi}_{\mathrm{i}}}(\mathrm{t}) \cdot \mathrm{B}_{\mathrm{Qi}}(\mathrm{t})
$$

where $f_{\mathrm{Qi}}(\mathrm{t})$ represents the appropriate percentages at time $\mathrm{t}$ which, applied to the loss reserve amounts $B_{Q i}(t)$ at time $t$ of the classes $i\left(i=1, \ldots, n_{v}\right)$, result in the capital required to cover future loss development deficiencies with «an adequate degree of probability».

This «adequate degree of probability» (the «Expected Policyholder Deficit (EPD) in the NAIC Actuarial Advisory Committee's concept) was originally set at $98.25 \%$ so that a permitted probability of loss of $1.75 \%$ for each separately considered risk category was considered as reasonable to be borne by the policyholders.

Because the 'true' development experience was unknown and could not readily be estimated, recourse was had to the reserve development experience of the US Property/Casualty insurers in the 18 accounting classes (including 4 reinsurance classes) over the past 10 years as an approximation thereto. A task force of the American Academy of Actuaries developed factors designed to produce the aforementioned degree of security. This resulted in a discounted $\mathrm{RBC}$ requirement e.g. in the case of Workers Compensation business of $9 \%$ of the reserves up to $28 \%$ in the case of Property reinsurance. For Liability reinsurance $10 \%$ was required.

Conversely, NAIC for a long time preferred an approach based, not on the probable values of negative variances but on the observed extreme values and which produced factors of $0.5 \%$ of the reserves for Workers Compensation insurance up to $34.8 \%$ of the reserves for liability reinsurance. The undiscounted liability extreme value was almost twice the amount required at the $98.25 \%$ confidence level and would thus result in a serious divergence after discounting.

The version finally promulgated was reworked on the basis of experienced statistics and, regrettably, the NAIC approach was largely adopted - for example the discounted $\mathrm{RBC}$ requirement for liability reinsurance was fixed at $37.8 \%$. This gave rise to an important point of criticism from the outset: the loss reserve RBC covered the deviations experienced in the past but not the potential for deviations in current circumstances.

The calculation rule for the factors $f_{\mathrm{Qi}}$ to be adopted for each individual class $\mathrm{i}\left(\mathrm{i}=1, \ldots, \mathrm{n}_{\mathrm{V}}\right)$ is based on an RBC factor weighted as to one half by the company's experience and as to one half by the industry experience from which the future investment income was eliminated (Present Value approach).

In addition to $f_{\mathrm{Qi}}$, all other variables are basically time dependent. For simplicity of description this time dependency is not explicitly referred to in formula (4.6) et seq. In 
practice the value of these variables will be determined in advance for each year of account.

$$
f_{\mathrm{Qi}}=\max \left\{0,\left[\left(\widetilde{f}_{\mathrm{Qi}} \cdot\left(0.5 \cdot \frac{\mathrm{CD}_{\mathrm{i}}}{\mathrm{ID}_{\mathrm{i}}}+0.5\right)+1\right) \cdot \mathrm{PV}_{\mathrm{Qi}}-1\right]\right\}
$$

Where:

$\widetilde{f}_{\mathrm{Qi}}=\mathrm{RBC}$ factor, notified by NAIC, required to cover the greatest experienced development deterioration in the previous 10 years for the industry as a whole in class $i$

$\mathrm{CD}_{\mathrm{i}}=$ The individual development factor (Company Development) from schedule $\mathrm{P}$ of the accounts of the company concerned for class $i$ from the last 9 years(so far as available) with a maximum of $400 \%$. For reinsurance category D only the first 5 of the last 9 years are considered

$\mathrm{ID}_{\mathrm{i}}=$ The industry development factor (Industry Development), notified by NAIC, for class $i$ from the last 10 years.

$\mathrm{PV}_{\mathrm{Qi}}=$ The present value factor, notified by NAIC, representing the average effect of discounting industry reserves at $5 \%$ interest.

If the development experience of the company concerned were to be identical to the industry experience, the determination of the factors reduces to:

$$
f_{\mathrm{Q}_{\mathrm{i}}}=\max \left[0,\left(1+\widetilde{f}_{\mathrm{Q}_{\mathrm{i}}}\right) \cdot \mathrm{PV}_{\mathrm{Q}_{\mathrm{i}}}-1\right]
$$

Given correct discounted reserves, where $\mathrm{PV}_{\mathrm{Qi}}=\frac{1}{1+\widetilde{f}_{\mathrm{Qi}}}$ it is possible to cover future development losses by investment income so that cover from risk capital is not needed. On the other hand allowance for actual hidden reserves where $\mathrm{PV}_{\mathrm{Qi}}<\frac{1}{1+\widetilde{f}_{\mathrm{Qi}}}$ is not allowed although, in principle reserves could be released from class $\mathrm{i}$ up to an amount of $\frac{1}{1+\widetilde{f}_{\mathrm{Qi}}}-\mathrm{PV} \mathrm{Q}_{\mathrm{Qi}}$ without endangering the level of security of class $\mathrm{i}$ in order, for instance, to compensate for negative developments in other classes. This gives rise to a further important point of criticism of the overall RBC concept. Where there is apparent 'over-reserving', a reduction in the existing reserves may be expected prior to the point of time of the calculation. Moreover, to the extent that the US market is in general assumed to be underreserved the $\mathrm{RBC}$ concept can thus lead to the situation being exacerbated.

This still holds after the adjustments to formula (4.5) which have to be made before the reserve $\mathrm{RBC}$ is introduced into the element $\mathrm{R}_{4}$ of the covariance formula.

The following adjustments, some of which are substantial, concern in detail:

\section{Determination of a deduction from (4.5) for "Loss-Sensitive-Contracts».}

For each class $i\left(i=1, \ldots, n_{V}\right)$ the percentage proportion $\beta_{Q i}$ of reserves for loss sensitive contracts to the total reserves $B_{\mathrm{Qi}}$ is calculated. To the extent of this proportion, the $\mathrm{RBC}$ 
originally derived by factor $f_{\mathrm{Qj}}$ is reduced by $30 \%$ in the case of direct insurance contracts and $15 \%$ in the case of reinsurance contracts in order to allow for the reduced development risk.

Formula (4.5) then becomes:

$$
\begin{aligned}
& \mathrm{R}_{\mathrm{Q}}=\sum_{\mathrm{i}=1}^{\mathrm{n}_{\mathrm{v}}} \hat{f}_{\mathrm{Q}_{\mathrm{i}}} \cdot \mathrm{B}_{\mathrm{Q}_{\mathrm{i}}} \\
& \text { with } \hat{f}_{\mathrm{Qi}}= \begin{cases}\left(1-0.30 \cdot \beta_{\mathrm{Qi}}\right) \cdot f_{\mathrm{Qi}} & \text { for direct insurance contracts } \\
\left(1-0.15 \cdot \beta_{\mathrm{Qi}}\right) \cdot f_{\mathrm{Qi}} & \text { for reinsurance contracts }\end{cases}
\end{aligned}
$$

An unambiguous definition of a «Loss-Sensitive-Contract» is however not simply stated.

2. Determination of an additional deduction for the 'medical malpractice' class.

For the proportion $\widetilde{\beta}_{\mathrm{Qj}}$ in respect of 'claims made' policies to the total reserves $\mathrm{B}_{\mathrm{Qj}}$ an additional deduction of $20 \%$ is allowed so that the factor $\hat{f}_{\mathrm{Qj}}$ for the class $\mathrm{j} \triangleq$ medical malpractice can be written as:

$$
\hat{f}_{\mathrm{Qj}}= \begin{cases}\left(1-0.30 \cdot \beta_{\mathrm{Oj}^{-}}-0.20 \cdot \widetilde{\beta}_{\mathrm{Qj}}\right) \cdot f_{\mathrm{Qj}} & \text { for direct insurance contracts } \\ \left(1-0.15 \cdot \beta_{\mathrm{Qj}}-0.20 \cdot \widetilde{\beta}_{\mathrm{Qj}}\right) \cdot f_{\mathrm{Qj}} & \text { for reinsurance contracts }\end{cases}
$$

In the case of a direct insurer with a medical malpractice portfolio consisting entirely of 'loss-sensitive' claims made policies, the basic $\mathrm{RBC}$ thus reduces to one half of the original amount for all subsequent calculations. This can be of considerable significance for specialist insurers in this sector.

\section{Adjustment for principal class of business.}

In the case of a widely diversified portfolio consisting of classes of similar importance, it is recognised that the consequential smoothing effect justifies a deduction from (4.5) before the application of the covariance formula. The detailed rule is as follows:

$$
\mathrm{R}_{\mathrm{Q}}=\left[0.7+0.3 \cdot \max _{\mathrm{k}}\left(\frac{\mathrm{B}_{\mathrm{Qk}}}{\sum_{\mathrm{i}=1}^{\mathrm{n}_{\mathrm{v}}} \mathrm{B}_{\mathrm{Qi}_{3}}}\right)\right] \cdot \sum_{\mathrm{i}=1}^{\mathrm{n}_{\mathrm{v}}} \hat{f}_{\mathrm{Qi}} \cdot \mathrm{B}_{\mathrm{Qi}}
$$

The weighting factor for $30 \%$ of the RBC will in this manner be determined by the maximum proportion one class bears to the total reserves. Thus, if 15 classes were all to account for identical proportions, this weighting factor would reduce to $1 / 15$ and of $30 \%$ only $2 \%$ would remain. $R_{\mathrm{Q}}$ would then only amount to $72 \%$ of the full product sum.

Conversely for a 'Monoline Insurer', the maximum is 1 and there is no deduction from the product sum.

\section{Loading for above aver age premium growth.}

An average growth of the Group Gross Written Premiums of $10 \%$ over the last 4 years is regarded as 'normal'. Growth in excess of $10 \%$ incurs an RBC loading of $45 \%$ up to a maximum rate of growth of $40 \%$. 
If the premium income of the most recent closed year of account is defined as GPI $(t)$, the growth factor $\mathrm{g}(\mathrm{t})$ is calculated as the arithmetic mean of the 3 last individual factors

$$
g(t)=\frac{1}{3} \cdot\left(\frac{G P I(t)}{G P I(t-1)}+\frac{G P I(t-1)}{G P I(t-2)}+\frac{G P I(t-2)}{G P I(t-3)}\right)
$$

The definitive formula for the pure reserve components of the $\mathrm{RBC}$ in the covariance formula, i.e. before consideration of the proportionate credit risk is thus:

$$
\overline{\mathrm{R}}_{4}(\mathrm{t})=\mathrm{R}_{\mathrm{Q}}(\mathrm{t})+\max \{0,[0.45 \cdot(\min (0.4 ; \mathrm{g}(\mathrm{t}))-0.1)]\} \cdot \sum_{(\mathrm{i}=1}^{\left(\mathrm{n}_{\mathrm{v}}\right.} \mathrm{B}_{\mathrm{Q}_{\mathrm{i}}}(\mathrm{t})
$$

At this point it should be emphasized that the risk loading for above average growth is calculated solely by reference to the premium growth and without reference to growth in reserves. This appears to be sensible because reserve growth can arise solely from realised development losses without any expansion of the business which indirectly would give rise to a stabilisation of reserves which would justify a deduction from the RBC.

\subsubsection{The premium risk}

The premium risk will be investigated in an analogous manner to the reserve risk. Based on the same classes $\mathrm{i}\left(\mathrm{i}=1, \ldots, \mathrm{n}_{\mathrm{V}}\right)$, percentage rates $f_{\mathrm{Pi}}(\mathrm{t})$ are determined for each class and associated with the net premium $B_{\mathrm{Pi}}(t)$ for the period $(t-1, t)$. The product gives the 'raw' premium RBC:

$$
\mathrm{R}_{\mathrm{P}}(\mathrm{t})=\sum_{\mathrm{i}=1}^{\mathrm{n}_{\mathrm{v}}} f_{\mathrm{P}_{\mathrm{i}}}(\mathrm{t}) \cdot \mathrm{B}_{\mathrm{P}_{\mathrm{i}}}(\mathrm{t})
$$

The bases for the determination of these factors are the loss ratios of the individual classes. The calculation rule, again leaving out the time parameter is:

$$
f_{\mathrm{P}_{\mathrm{i}}}=\max \left\{0,\left[\widetilde{f}_{\mathrm{P}_{\mathrm{i}}} \cdot\left(0.5 \cdot \frac{\mathrm{CL}_{\mathrm{i}}}{\mathrm{IL}_{\mathrm{i}}}+0.5\right) \cdot \mathrm{PV}_{\mathrm{P}_{\mathrm{i}}}+\mathrm{CE}_{\mathrm{i}}-1\right]\right\}
$$

By general analogy with (4.6) the variables are:

$\widetilde{f}_{\mathrm{Pi}}=$ Maximum industry loss ratio to be covered by $\mathrm{RBC}$, as notified by NAIC

$\mathrm{CL}_{\mathrm{i}}=$ Individual average loss ratio (Company Average Loss and Loss Adjustment Expense Ratio) in class $i$ for the company concerned averaged over the last 10 years if available. As the unweighted average is made up of the individual loss ratios, years with a lower premium volume than $20 \%$ of the average may be left out of account. Given more than two such years the experience of the company need not be taken into account at all. Further, individual loss ratios are limited to $300 \%$ before inclusion in the average calculation.

$\mathrm{IL}_{\mathrm{i}}=$ Average industry loss ratio (Industry Average Loss and Loss Adjustment Expense Ratio) in class i for the last 10 years as notified by NAIC 
$\mathrm{PV}_{\mathrm{Pi}}=$ The present value factor representing the average effect of discounting the premiums net of expenses at $5 \%$ interest (as notified by NAIC)

$\mathrm{CE}_{\mathrm{i}}=$ Actual underwriting expense ratio (Company Underwriting Expense Ratio) of the company concerned in class $i$.

If the average loss ratio of the company concerned were to be identical to the average loss ratio of the industry, (4.12) reduces to:

$$
f_{\mathrm{P}_{\mathrm{i}}}=\max \left[0,\left(\widetilde{\mathrm{f}_{\mathrm{i}}} \cdot \mathrm{PV}_{\mathrm{P}_{\mathrm{i}}}+\mathrm{CE}_{\mathrm{i}}-1\right)\right]
$$

so that, on the basis of adequate discounted premiums where $\mathrm{PV}_{\mathrm{Pi}} \cdot \widetilde{f}_{\mathrm{Pi}_{i}}=1-\mathrm{CE}_{\mathrm{i}}$, the underwriting losses will be fully covered by the premiums paid and the interest income thereon up to a maximum loss ratio of $\widetilde{f}_{\mathrm{Pi}}$ and in this event cover from the RBC is not required. In this expression 1-CE $\mathrm{CE}_{\mathrm{i}}$ represents the proportion of the premiums net of expenses which will earn interest up to the time of claims payment.

Here again, a similar objection arises as in the case of the reserve RBC. A more than adequate premium does not give rise to a reduction in the $\mathrm{RBC}$ for other $\mathrm{RBC}$ categories, as the minimum value in the calculation is 0 . It follows that an additional security margin in the premium is of little value in relation to the RBC. This can only be understood having regard to the importance some insurance commissioners attach to the maintenance of lower premiums in the interests of consumer protection. In the light of the massive obstacles placed in the way of necessary premium alterations, one must regard the achievement of the net risk premium as progress. Further, cross-subsidies of different classes are not approved of.

The adjustments to (4.11) are largely analogous to those of the reserve RBC and only the important aspects are discussed below. Firstly, in the case of loss-sensitive contracts a reduction arises from the substitution of the factors $f_{\mathrm{Pi}}$ by $\hat{f}_{\mathrm{Pi}}$ where:

$$
\hat{f}_{\mathrm{Pi}}=\left\{\begin{array}{l}
\left(1-0.30 \cdot \beta_{\mathrm{Pi}}\right) \cdot \mathrm{f}_{\mathrm{P}_{\mathrm{Pi}}} \text { for direct insurers } \\
\left(1-0.15 \cdot \beta_{\mathrm{Pi}}\right) \cdot \mathrm{f}_{\mathrm{P}_{\mathrm{Pi}}} \text { for reinsurers }
\end{array}\right.
$$

where $\beta_{\mathrm{Pi}}$ represents the percentage proportion of loss-sensitive policies to the total net premiums for class $i$.

In relation to the proportion $\widetilde{\beta}_{\mathrm{Pj}}$ in respect of premiums under claims-made policies in class $\mathrm{j} \triangleq$ Medical Malpractice, a separate reduction of $20 \%$ is granted.

Similarly, the consideration given to the diversification of the portfolio is fully analogous to (4.8) allowing for the class weighted premium distribution:

$$
\mathrm{R}_{\mathbf{P}}=\left[0.7+0.3 \cdot \max _{\mathrm{k}}\left(\frac{\mathrm{B}_{\mathrm{Pk}_{\mathrm{k}}}}{\sum_{\mathrm{i}=1}^{\mathbf{n}_{\mathrm{v}}} \mathbf{B}_{\mathrm{P}_{\mathrm{i}}}}\right)\right] \cdot \sum_{\mathrm{i}=1}^{\mathrm{n}_{\mathrm{v}}} \hat{f}_{\mathrm{P}_{\mathrm{i}}} \cdot \mathrm{B}_{\mathrm{Pi}_{\mathrm{i}}}
$$


Again, if premiums are distributed evenly over 15 classes a deduction of $28 \%$ results whereas insurers who only operate in one branch obtain no reduction.

Finally, the premium growth $\mathrm{g}(\mathrm{t})$ resulting from (4.9) is also used to calculate a loading on the premium $\mathrm{RBC}$ for above average growth. In this case the factor to be applied to the premiums is $22.5 \%$, being one-half of the reserve factor. The definitive formula for the $\mathrm{RBC}$ covering the total rating risk, analogous to (4.10) is:

$$
R_{5}(t)=R_{P}(t)+\max \{0,[0.225 \cdot(\min (0.4 ; g(t))-0.1)]\} \cdot \sum_{i=1}^{n_{V}} B_{P_{i}}(t)
$$

It is surprising that the growth rate of $10 \%$, identical to that for the reserve $\mathrm{RBC}$, is regarded as 'normal' notwithstanding the fact that, particularly in the Casualty sector, the reserve growth, given normal development, may be significantly greater than the premium growth.

The risk components identified earlier in (2.2) above by the premium development $\mathrm{P}(\mathrm{t})$ and the claims development $\mathrm{X}(\mathrm{t})$ should be comprehensively covered by the foregoing considerations of the reserve risk and the rating risk. It will however be seen from section 6 below that, apart from the weaknesses already mentioned, this is not adequately achieved. Nevertheless the attempt must be regarded as remarkable. It does however require some refinement if it is to fit the concept of a risk-justified capital requirement to cover the underwriting risk.

\subsubsection{The asset risk}

The risk of fluctuations of investment income, expressed in (2.2) as $\mathrm{Y}(\mathrm{t})$ is of less significance overall than the reserve risk and the premium risk for Property/Casualty insurers in USA. It has however been extensively examined in the light of the RBC consideration in the Life/Health sector published a year earlier. As a consequence, some of the following analyses demonstrate a seemingly unjustifiable degree of detail.

The unadjusted basic amount of the investment RBC is calculated analogously to formula (4.5):

$$
\mathrm{R}_{\mathrm{K}}(\mathrm{t})=\sum_{\mathrm{i}=1}^{\mathrm{n}_{\mathrm{k}}} f_{\mathrm{K}_{\mathrm{i}}}(\mathrm{t}) \cdot \mathrm{B}_{\mathrm{K}_{\mathrm{i}}}(\mathrm{t})
$$

This amount can be broken down into the three components, investments in affiliated companies, investments in fixed interest securities (including short-term investments) and investments in equities (including property and other investments) which in turn provide the three elements $R_{0}(t), R_{1}(t)$ and $R_{2}(t)$ in the covariance formula (see Exhibit 4 ). Here again, in the interests of simplification, the time dependency is not explicitly discussed. 
Affiliated

$$
\text { Fixed interest }
$$

Shares, property

Companies Securities and other investments

$$
\begin{aligned}
& \mathrm{R}_{\mathrm{K}}=\overline{\sum_{\mathbf{i}=1}^{\mathrm{n}_{0}} f_{\mathrm{K}_{\mathbf{i}}} \mathbf{B}_{\mathrm{K}_{\mathbf{i}}}}+\overline{\sum_{\mathbf{i}=\mathbf{n}_{\mathbf{0}}+1}^{\mathbf{n}_{1}} f_{\mathrm{K}_{\mathbf{i}}} \mathbf{B}_{\mathrm{K}_{\mathbf{i}}}}+\overline{\sum_{\mathbf{i}=\mathbf{n}_{1}+1}^{\mathbf{n}_{\mathrm{k}}} f_{\mathrm{K}_{\mathbf{i}}} \mathbf{B}_{\mathrm{K}_{\mathbf{i}}}} \\
& =>R_{0} \quad \quad \quad=>R_{1} \quad=>R_{2} \quad \text { (covariance group) }
\end{aligned}
$$

The basic values $\mathrm{B}_{\mathrm{Ki}}$ are in general the balance sheet values of the different investment categories, in USA the current market values. The factors $f_{\mathrm{Ki}}$ directly reflect the degree of security of the respective type of investment. This is clearly evident in the case of the second component, the fixed interest securities (see Exhibit 6): Federal Government Bonds are considered to be absolutely secure and carry a factor 0 . Thereafter the percentage rates increase from $0.3 \%$ to $1 \%, 2 \%, 4.5 \%$, up to $10 \%$ for 'Lower Quality' loans and $30 \%$ for loans in or near default.

\section{RBC-Factors for US-Property/Casualty Insurers Factors for Fixed Income Bonds (Covariance Category $R_{1}$ )}

\begin{tabular}{|l|c|}
\hline Bond Category $B_{K_{1}}$ & Factor $\mathbf{f}_{K_{1}}$ \\
\hline Federal Government Bonds & 0,000 \\
\#1 Highest Quality & 0,003 \\
\#2 High Quality & 0,010 \\
\#3 Medium Quality & 0,020 \\
\#4 Low Quality & 0,045 \\
\#5 Lower Quality & 0,100 \\
\#6 In/Near Default & 0,300 \\
\hline
\end{tabular}

\section{Exhibit 6}

For the first component in (4.17), governing the RBC necessary for affiliated companies, the factor is, as far as possible, derived from the $\mathrm{RBC}$ of the companies concerned, whether they are affiliated insurance companies themselves subject to the $\mathrm{RBC}$ regulation or investment companies whose categories of investment are evaluated by the $\mathrm{RBC}$ formula. For ordinary shares the equation $f_{\mathrm{Ki}} \cdot \mathrm{B}_{\mathrm{Ki}}=\beta_{\mathrm{Ki}} \cdot \mathrm{RBC}_{\mathrm{Ki}}$ holds, where $\beta_{\mathrm{Ki}}$ represents the percentage holding and $\mathrm{RBC}_{\mathrm{Ki}}$ is the $\mathrm{RBC}$ of the affiliated company $\mathrm{K}_{\mathrm{i}}$ calculated by the evaluation 
rules. In the case of preference shares and loan capital $\mathrm{RBC}_{\mathrm{Ki}}$ is replaced by the "excess $R B C$ ' being the excess of the relevant $R B C$ over the market value of the ordinary shares.

In any event, the balance sheet value of the relevant holding forms an upper limit for the $\mathrm{RBC}$ value as this represents the maximum possible write-down.

For foreign insurance companies a standard factor of $50 \%$ is applied to the balance sheet value and for other holdings a factor of $22.5 \%$ In the case of voting shares (as part of the third group in (4.17)) the present regulation prescribes a standard evaluation factor of $5 \%$ whereas the original proposals envisaged a scale of factors from $0.3 \%$ to $30 \%$ similar to fixed interest securities.

For non-voting 'Money Market Funds' a factor of $0.3 \%$ applies and for all other nonvoting shares $15 \%$.

Finally, all other investments are evaluated with factors between $0.3 \%$ (for 'Cash' and 'Short Term Investments' as components of the covariance group $\mathrm{R}_{1}$ ), $5 \%$ for mortgages and secured loans (also group $\mathrm{R}_{1}$ ) and $10 \%$ for property (group $\mathrm{R}_{2}$ ).

Adjustments analogous to (4.8) and (4.14) are also made to the different investment categories before the application of the covariance formula to take into account the evenness of the distribution of the portfolio under consideration.

Firstly the $\mathrm{RBC}$ in respect of the 10 largest investments carrying a significant degree of risk is doubled up to a maximum factor of $30 \%$. An investment $\mathrm{K}_{\mathrm{i}}$ is considered to carry a significant degree of risk if

$$
f_{\mathrm{Ki}} \geq 0.01
$$

Federal Government and 'Highest Quality' Bonds are not considered to carry any additional risk and are excluded. Investments in affiliated companies are, in general, not taken into account.

In respect of each individual investment $K_{i}, i \in\left(n_{0}+1, \ldots, n_{K}\right)$ which forms part of one of the 10 largest investment entities e.g. different bonds of the same issuer or different mortgages of the same borrower, $f_{\mathrm{Ki}}$ is replaced by

$$
\hat{f}_{\mathrm{Ki}}=\min \left(0.3 ; 2 \cdot f_{\mathrm{Ki}}\right)
$$

A further adjustment is made in respect of fixed interest securities according to the number of issuers represented in the portfolio. In determining the weighted loading factor h, the first 50 issuers, excluding 'Federal Government' and 'Higher Quality' Bonds are loaded $150 \%$ and the next 50 are loaded $50 \%$. No loading arises in respect of the next 300 issuers and over and above issuer number 401 a reduction of $10 \%$ is allowed so that given $\mathrm{nE}$ issuers where $n_{E}>400$ the following calculation rule applies:

$$
\begin{aligned}
h & =\frac{50 \cdot 2.5+50 \cdot 1.3+300+\left(n_{E}-400\right) \cdot 0.9}{n_{E}} \\
& =\frac{490+\left(n_{E}-400\right) \cdot 0.9}{n_{E}}=0.9+\frac{130}{n_{E}}
\end{aligned}
$$


If the relevant portfolio consists of fewer than 1300 issuers $h$ operates as a true loading factor. Above 1300 issuers, however, it operates as a reduction; if $n_{E}=1300$ there is no adjustment.

The determining factors for the asset risk, described above, essentially comprehend the components $\mathrm{Y}(\mathrm{t})$ and $\mathrm{V}(\mathrm{t})$ in $(2.2)$ which describe the investment income and the incidental proceeds of disposals and/or revaluations up to point of time $t$, where $Y(t)$ accounts for the interest risk and $\mathrm{V}(\mathrm{t})$ the risk of changes in value. The $\mathrm{RBC}$ regulation thus attempts to allow for these two risk components simultaneously. This may be justified in the context of US accounting methods as the current market value principle reflects the interdependence of the two risk components reasonably correctly. Where, however, the lowest value principle applies, such an approach would be more problematical as, with falling interest rates, the increases in value are not automatically available as balancing components. In this event the risk of changes in value must be independently modelled.

\subsubsection{The credit risk}

The treatment of the credit risk provoked the most vehement discussion prior to the promulgation of the current regulation. This risk arises primarily in respect of claims against reinsurers which predominates in the credit risk calculation spectrum.

The $10 \%$ standard factor applied in the first stage of the calculation and the subsequent treatment of the credit RBCs in the covariance formula provide ample grounds for further discussion.

In comparison with the effort involved in differentiating the asset risk described in 4.2.5 above it seems more than unsatisfactory that in the formula

$$
\mathrm{R}_{\mathrm{F}}(\mathrm{t})=\sum_{\mathrm{i}=1}^{\mathrm{n}_{\mathrm{F}}} f_{\mathrm{F}_{\mathrm{i}}}(\mathrm{t}) \cdot \mathrm{B}_{\mathrm{Fi}_{\mathrm{i}}}(\mathrm{t})
$$

a constant factor $f_{\mathrm{Fi}}=0.1$ is applied to the total $\mathrm{B}_{\mathrm{F} 1}$ of all reinsurance receivables. The vital importance in the reinsurance sector of differentiating between the solvency of different reinsurers is here ignored as also is differentiation according to settlement times, type of contract, basis of security (e.g. cash deposits, letters of credit) or other significant factors governing the creditworthiness of reinsurance receivables.

This lack of differentiation appears even more serious against the background of the further treatment of the credit risk in the covariance formula. As a result of the eventual compromise of building one-half of the credit risk into the reserve risk (see (4.4)), variations in the credit risk exert a much greater influence on the total RBCs than would be the case if the credit risk were separately allowed for within the covariance formula.

At this point one can forecast that, in the light of the first experiences with the calculation and effect of $R_{F}(t)$, modifications will quickly be made which will relate $R_{F}(t)$ to the actual risk. The aim should be to define $R_{F}(t)$ with sufficient accuracy that the outcome of the premium development $\mathrm{P}(\mathrm{t})$ and the claims development $\mathrm{X}(\mathrm{t})$ for own account in (2.2) reflects the 'true' net position of the company, having full regard to the credit risk of outstanding reinsurance claims. 


\section{Sensitivity tests of the $\mathrm{RBC}$ development}

For simplicity, the square root term in the covariance formula (4.4) is first expressed as a single term:

$$
\begin{aligned}
R_{1 \ldots 5}(t):=\sqrt{\sum_{i=1}^{5} R_{i}^{2}(t)} & =\sqrt{R_{i}^{2}(t)+R_{2}^{2}(t)+\left(0.5 R_{F}(t)\right)^{2}+\left(0.5 R_{F}(t)+\bar{R}_{4}(t)\right)^{2}+R_{5}^{2}(t)} \\
& =\sqrt{R_{i}^{2}(t)+R_{2}^{2}(t)+0.5 R_{F}^{2}(t)+R_{F}(t) \cdot R_{4}(t)+\bar{R}_{4}^{2}(t)+\bar{R}_{5}^{2}(t)}
\end{aligned}
$$

Following the resubstitution of $R_{F}$ and $\bar{R}_{4}$, a partial differential is then derived for each single element of the $\mathrm{RBC}$ as follows:

(5.2)

$$
\begin{aligned}
& \frac{\partial R B C(t)}{\partial R_{0}(t)}=1 \\
& \frac{\partial R_{B C}(t)}{\partial R_{i}(t)}=\frac{R_{i}(t)}{R_{1 . . .5}(t)} i=1 . . .5
\end{aligned}
$$

This marginal analysis will demonstrate the extent to which an increased RBC element in a sub-category affects the total $\mathrm{RBC}$ requirement.

Obviously an increase in the RBCs in the sector $R_{0}$, i.e. the affiliated companies, will always result in an increase in the overall $R B C$ requirement of the same amount.

In the categories $\mathrm{R}_{1}$ to $\mathrm{R}_{5}$, however, each additional $\mathrm{RBC}$ dollar in a sub-category will only result in an increase in the overall $\mathrm{RBC}$ requirement to the extent that this category contributes to the result of the square root term $R_{1} \ldots 5(t)$. In other words, substantial $R B C$ categories impact fully whereas RBC categories which are unimportant in terms of amount (but not necessarily in terms of risk!) have little impact on the total requirement.

In this respect the estimation of the credit risk creates a particular difficulty as this is treated independently only to the extent of one-half, the other half being included in the reserve risk. It is therefore appropriate to consider the following partial differentials:

$$
\frac{\partial R B C(t)}{\partial R_{F}(t)}=\frac{R_{F}(t)+\bar{R}_{4}(t)}{2 \cdot R_{1 \ldots 5}(t)}=\frac{R_{3}(t)+R_{4}(t)}{2 \cdot R_{1 \ldots 5}(t)}
$$

$$
\frac{\partial R B C(t)}{\partial \bar{R}_{4}(t)}=\frac{\bar{R}_{4}(t)+0,5 R_{F}(t)}{R_{1 \ldots 5}(t)}=\frac{R_{4}(t)}{R_{1 . . .5}(t)}
$$

These two expressions demonstrate the effect of an independent $\mathrm{RBC}$ alteration arising from the credit risk (e.g. from greater reinsurance cessions) as well as that of an independent alteration of the reserve risk alone. Whilst it has no effect on the reserve risk whether and to what extent the credit risk arises, on the other hand the credit risk is exposed to a significant impact from the reserve risk. 
Exhibit 7 sets out an example of the calculation for a 'typical' US company which demonstrates that an increase of one dollar in the $\mathrm{RBC}$ in category $\mathrm{R}_{3}$ results in an increase in the total RBC of only 8.63 cents, whereas an analysis on the basis of formula (5.3) shows that an additional one dollar increase in the $\mathrm{RBC}$ requirement for reinsurance receivables results in an increase in the total $\mathrm{RBC}$ of 47.39 cents. As a constant factor of $10 \%$ applies to reinsurance receivables, each additional dollar therein results in an increase in the $\mathrm{RBC}$ of 4.739 cents. From the standpoint of the $\mathrm{RBC}$ this is therefore the minimum reduction that must arise in the reserve risk and/or premium risk area as a result of reinsurance cessions.

\section{Summary and outlook}

\subsection{Critique on the credit risk}

It seems somewhat incomprehensible to carry out an RBC allocation for the asset risk in the greatest detail but to retain a simplistic approach to the significantly more influential credit risk in the covariance formula.

This criticism naturally stands or falls with the covariance formula itself. The disproportionate influence of the credit risk on the total $\mathrm{RBC}$ arises from its 'last minute' coupling with the reserve risk which has certainly not yet been analyzed in this form.

It remains to be seen which direction the inevitable reaction will follow: A further alteration to the covariance formula or, what is in any event to be welcomed, a differentiation of the reinsurance claims risk. In this connection, in addition to a differentiation of the factor $f_{\mathrm{Fi}}$ e.g. depending on the 'rating' of the reinsurer, consideration could also be given to the inclusion of a compensatory effect, analogous to the other risk categories, which could be applied in the form of a weighting factor based for example on the number of reinsurers.

\subsection{Unconsidered risk components}

More serious than variations in the detail with which the components included are differentiated, seems to be the effect of risk components which, until now, have not been explicitly considered. Above all other, the accumulation risk which, particularly for US Property insurers, constitutes a significant element in the random variable $P(t)-X(t)$ in (2.2). The accumulation risk arises in practice where one event can affect a large number of risks which are thereby positively correlated with each other.

Thus local concentrations of sums insured can form a significant separate component of risk, particularly in areas exposed to natural catastrophes, which time and again has been demonstrated by the numerous insolvencies following large natural catastrophes in USA. It is therefore inexplicable that there is no RBC component for the natural catastrophe risk. Such a component must include a measure of geographical concentration based on a similar concept to that in the investment area.

A further risk component not explicitly covered is the expense risk defined as $K(t)$ in (2.2). This undoubtedly gives rise to a capital requirement and thus requires its separate $\mathrm{RBC}$ factor which would recognise the potential for fluctuating business expenses. 


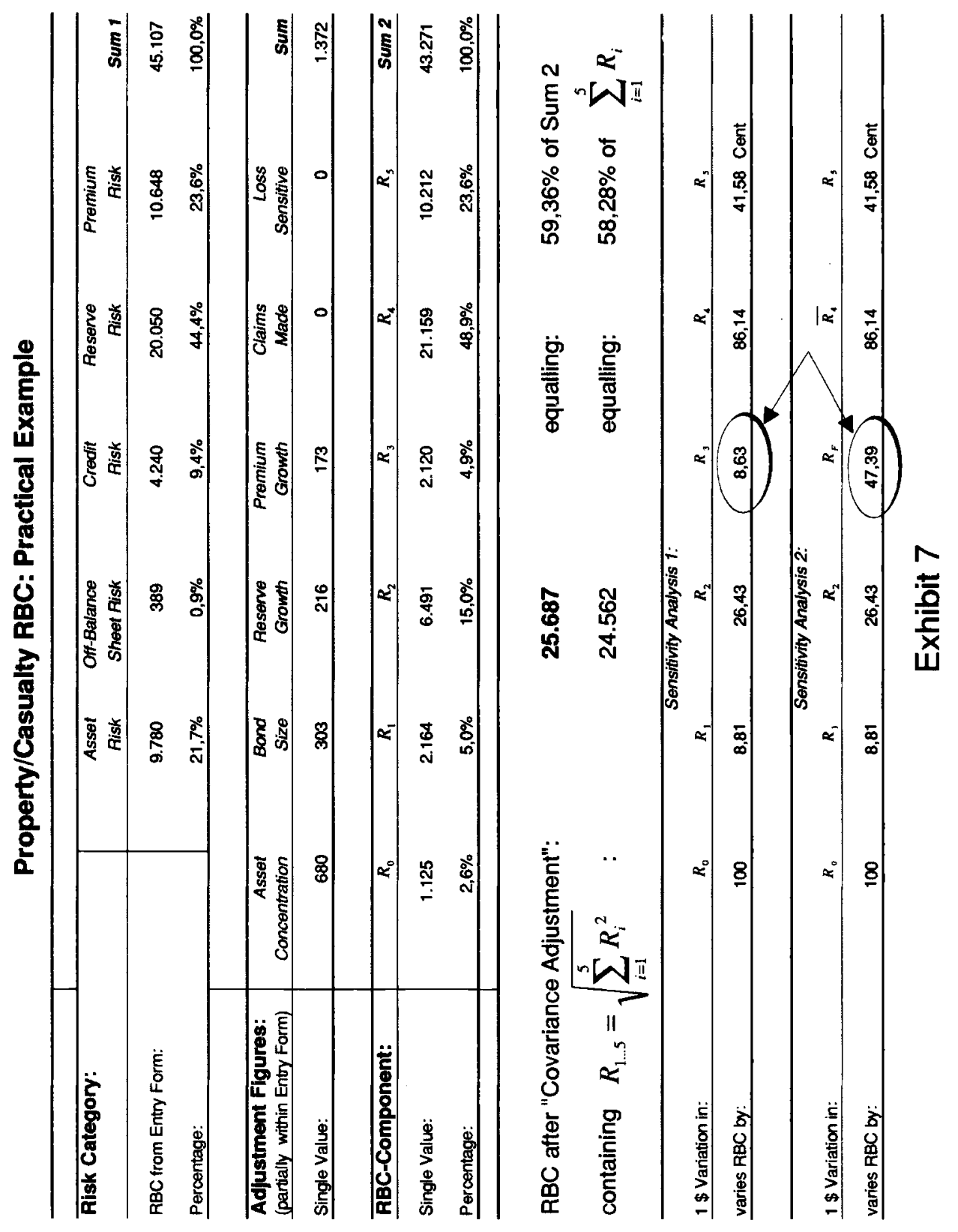


Similarly consideration of the liability risk, apart from 4.2.3.1 and 4.2.3.2, is lacking. In the USA in particular this risk is affected by judicial decisions which are difficult to predict. Whether this can sensibly be estimated is not for discussion here but that it is a very important factor in the assessment of an insurer underwriting liability business is demonstrated by the special report in Best's Review of May 1994 which concluded that the underreserving in respect of environmental and asbestos risks amounted to US $\$ 260 \mathrm{bn}$. The discounted value of this under-reserving was estimated at US\$132bn. and represented almost $3 / 4$ of the US $\$ 183 \mathrm{bn}$. total available surplus of the Property/Casualty insurers.

Finally the 'management risk' is also an element of the general entrepreneurial risk, the measurement and evaluation of which is by its nature extremely problematical. It must nevertheless be apparent that an RBC analysis of the actual situation, however sophisticated, will give no protection against serious management failures which would lead directly to the «Mandatory Control Level» if they could be identified and appropriately weighted in an assessment system.

\subsection{Effect on the behaviour of participants in the market}

In spite of all the criticisms, the promulgation of the RBC system has given rise to intensive discussion of the significance of the adequacy of risk capital and its determinant components and has apparently resulted in furthering this desirable development. In future, more serious consideration will have to be given to the effect of entrepreneurial decisions on the RBC requirement. This can benefit premium rating levels as well as the conscious attention to individual weighted risk components which can be favourably influenced, for example by means of reinsurance. Conversely, many of the present causes for concern will evaporate at the latest when the manner of thinking which has given rise to them is seen to be of secondary importance in the light of the first practical experience. After the many verbal arguments there must now be some intensive calculations in the years to come before market participants develop in their own minds a feeling for their 'own' risk reserve process and its determinant components. 


\section{REFERENCES}

Actuarial Advisory Committee to the NAIC P/C Risk-Based Capital Working Group: Report on Covariance Method for Property / Casualty Risk-Based Capital, Casualty Actuarial Society Forum, Summer 1993, p. 173 ff.

American Academy of Actuaries Property / Casualty Risk-Based Capital Task Force: Report on Reserve and Underwriting Risk Factors, Casualty Actuarial Society Forum, Summer 1993 Edition, p. $105 \mathrm{ff}$.

American Academy of Actuaries Property / Casualty Risk-Based Capital Task Force: Proposed RiskBased Capital Interest Rate Risk Charge, April 1994.

BALliNG, J. and LEVIN, A.: Risk-Based Capital: A Property / Casualty Perspective, Focus, edited by Standard \& Poor's Insurance Rating Services, August 1993, p. 35 ff.

BANHAM, R.: Risk-Based Capital Standards Point the Way, Focus, edited by Standard \& Poor's Insurance Rating Services, June 1993, p. $37 \mathrm{ff}$.

BRENDER, A., BROWN, R. and PANJER, H.: A Synopsis and Analysis of Research on Surplus Requirements for Property and Casualty Insurance Companies, Casualty Actuarial Society Forum, Summer 1993 Edition, p. 1 ff.

COVALESKI, J. M.: Regulators Soften Their October Surprise, Best's Review, January 1994, p. 42 ff.

FINNIS, D.: Risk-Based Capital - A Report on Progress, General Insurance Update, edited by Tillinghast, August 10th, 1993.

FINNIS, D.: Risk-Based Capital - An Aid to Internal Financial Planning? General Insurance Update, edited by Tillinghast, October 29th, 1993.

GREENWALD, J.: Fallout from Formula, Business Insurance, February 14th, 1994, p. 1 and p. 25 ff.

HEILMANN, W.-R.: Grundbegriffe der Risikotheorie, Karlsruhe 1987.

HESBERG, D.: Solvabilität als Gegenstand der Risikopolitik, Zeitschrift für die gesamte Versicherungswissenschaft, 1983, p. 255 ff.

KARTEN, W.: Grundlagen eines risikogerechten Schwankungsfonds für Versicherungsunternehmen, Berlin 1966.

KARTEN, W.: The New «Schwankungsrückstellung» in Annual Statements of German Insurers - An Application of the Theory of Risks? Geneva Papers of Risk and Insurance, No. 17, 1980, p. 54 ff.

LISKOV, R. and PARK, R.: Are the NAIC's Risk Based Capital Model Acts Constitutional? Insurance and Reinsurance Law, edited by Chadbourne \& Parke, Winter 1994, p. 3 f.

MÜLLER, E.: Risk-Based Capital für Versicherungsunternehmen. Der amerikanische Ansatz, Zeitschrift für Versicherungswesen, Rückversicherungssonderheft No 21, November 1995.

MÜLLER, E. and REISCHEL, M.: Vom theoretischen Konzept des Risikoreserveprozesses zur praktischen Messung und Steuerung des Risikokapitals (Risk-Based Capital) in: «Risiko, Versicherung, Markt», Festschrift für Walter Karten zur Vollendung des 60. Lebensjahres, Karlsruhe 1994, p. $465-500$.

NAIC: NAIC Life Risk Based Capital Report, Overview and Instructions for Companies, May 1st, 1993.

NAIC: Property / Casualty Risk-Based Capital Formula, Exposure Draft - June 1993.

NAIC: Property / Casualty Risk-Based Capital Formula, Exposure Draft - October 1993.

NAIC: Risk-Based Capital (RBC) for Insurers Model Act, Draft, Nov. 23rd, 1993. 
N.N.: Impact of Catastrophes on US Property Insurance, Catastrophe Reinsurance Newsletter, No. 12, February 1994, p. 30.

N.N.: NAIC Unveils Property / Casualty Capital Standards, DYP Insurance \& Reinsurance Solvency Report, No. 104, July 6th, 1993, p. 286 ff.

N.N.: P \& C Risk-Based Capital Working Group Minutes, November 22nd / 23rd, 1993.

N.N.: RAA unhappy with capital formula,The Re Report, December 6th, 1993.

N.N.: Risk-Based Capital Standards for Property / Casualty Insurers: Potential Impact on Creditworthiness, Moody's Special Comment, edited by Moody's Investors Service, May 1994.

PUCCIA, M.: Building a better Mouse-Trap: S \& P's revised Risk-Based Capital Model, Focus, edited by Standard \& Poor's Insurance Ratings, September 1993, p. $1+$ p. 5 ff.

REISCHEL, M.: Dynamische Rückversicherungs- und Ausschüttungspolitik beim Risikogeschäft, Karlsruhe 1981.

SCHRADIN, R. and TELSCHOW, I.: Solvabilitätskontrolle in der Schadenversicherung. Eine betriebswirtschaftliche Analyse der Risk-Based Capital (RBC)-Anforderungen in den Vereinigten Staaten, Mannheimer Manuskripte zu Versicherungsbetriebslehre, Finanzmanagement und Risikotheorie Nr. 78, Mannheim 1995.

SIMPSON, E. M. and KELLOGG, P. B.: NAIC's RBC: A virtual Reality, Best's Review Property / Casualty, February 1994, p. 49 ff.

SNYDER, H. and SMITH, D. W.: Environmental / Asbestos: The Industry's Black Hole, Best's Review Property / Casualty, May 1994, p. 35 ff. 